\title{
Effect of Democratic Coaching Style on Badminton Players in the Tournaments' Competition
}

\author{
* Mr. Nisar Ahmed Khaskheli (Corresponding Author) \\ ** Dr. Hakim Ali Sahito \\ ** Mr. Muhammad Hashim Darya
}

\begin{abstract}
The focal subject of the examination was to know the effect of a democratic coaching style with the certainty of the players to compete while playing matches. The competitors (20) from SALU, Khairpur, and college as 100 from each $(N=200)$ partook in the examination on the recommended by the relevant Director Sports and inter-varsity rivalries where the competitions in the shape of interdepartment were arranged accordingly. A survey questionnaire was used as an information assortment instrument. The frequencies, percentages were diversely computed with the general means as; 2.37, 2.34, 2.51 which were fundamentally different from one another. The results mean that a huge bit of players was experienced for the nearest and beneficial outcomes of democratic coaching style on the skills of the capability to compete of players. The current research suggested that the coaching and training programs generate and develop confidence level of players to contend suitably ought to be masterminded and the competitions like between club, Inter-district, inter-region, Interprovince school, inter-department, inter-collegiate and inter-varsity be sorted out where the players may benefit open doors for cooperation and may show their degree of ability to compete in the tournaments.
\end{abstract}

\section{Keywords: Democratic Coaching, Competition, Effect Assessment}

\section{Introduction}

The rise of training psychology in sports were described since two thousand has been altogether added to the improvement of a proof-based methodology and a longing for a more grounded hypothetical system (Latham, 2007), has been also one of the most famous research issue (Grant et al., 2010). In sports, a mentor proceeds to prepare players to fit as a fiddle of coach, educator, persuasive, executive, boss, and advocate and may have different jobs. The coaching in sports assumes an essential job in the ability advancement of the players of any occasion and has become a significant circumstance for the games exercises experts, sports exercise institutions, and all departments which are concerned with the sports associations. Better training in a profitable way advances the specialized abilities and various basic methods in stand-out games. So also in sports like Badminton, the training in the shape of coaching shows essential jobs of advancing strategies, aptitudes, capacity to compete, capacity to chart an awesome game approach, affectivity of better impacts fundamental to triumphant positions, and extreme consequences of carrying on with cooperative people, authorities, adversaries, and onlookers (Dunning et al., 1989). In any case, the underlying foundations of such obvious arrogance in relative capacity and the comparing benefits that may clarify the diligence of the wonder are not clear yet. One individual advantage is the utilization estimation of the conviction that one is skilled (or "inner self utility," Koszegi 2006). Similarly, individuals feel better with an ideal selfdiscernment, even at the expense of being presumptuous and along these lines settling on wrong decisions. Individuals likewise get advantage from arrogance comparable to social picture worries, as they want that others consider them to be being gifted (Burks et al., 2013).

* Department of Physical Education and Sports Sciences., Sukkur IBA University

Email: nisar.khaskheli@iba-suk.edu.pk

** Department of Zoology at DPRI, Faculty of Natural Sciences., SALU- Khairpur

Email: hakim.sahito@salu.edu.pk

*** Department of Physical Education and Sports Sciences., Sukkur IBA University

Email: m.hashim@iba-suk.edu.pk 


\section{Coaching}

The word coaching was first utilized in mid of the fifteenth century in the Hungarian town of Kocs (articulated "mentor"), thereafter this word coach spread everywhere throughout Europe. By mid of nineteenth-century word coach was utilized by oxford University slang for a guide; one who brings or urges his understudies through a test. The word additionally show up in the progress of George Eliot, an English writer, who was lady, the genuine name was Marry Anne, similar to the Sports Coach, the oxford coach looked to some extent like the advanced rendition, just training and bestowing information as would any skillful educator on traditional lines. An educating and learning process wherein two individuals may contact with one another, one individual has data and different needs direction and bearing (Renton, 2009). The advancement coaching term, the developing accomplishment of expert bodies liable for affirming mentors, and the maximum quantity of people rehearsing as mentors, demonstrates that the action includes a common personality. Anyway, despite this our insight into numerous parts of coaching stays unexplored (Palmer \& McDowall, 2010). The sports training exercises is characterized as a lot of methodologies expected to upgrade the coach's capacity to impact the conduct of players more successfully (Smith, 2010). A powerful training is the ability to treat players in befitting habits, players have singular aptitudes and legitimacy for his/her uniqueness, every single member should be stirred disparately (Pilus \& Saadan, 2009). The Coaching in sports exercises has been ended up being set of arranging and procedures chose to beautify the capability of training to affect the general execution of complete gathering and competitors all the more accurately (Smith, 2010). In sports, the instructing is basic to ensure greatness competitors in a challenge. The training execution is intended to improve the exhibition of an individual (Whitmore, 2002). The Coach may have an indispensable impact in a person's life as they incorporate capacity which could impacts decidedly or contrarily on the game's execution of players (Bruner et al., 2011). Coaching is an expert endeavor that permits the players to partake in sports rivalries with viable practices (McDonell, 2016; Khaskheli et al., 2019).

\section{Competition}

The relationship of coaching with players' capacity to contend implies aptitudes of the coach to affect the planning of players for rivalry (Kavussanu et al., 2008), Development of the competitor's certainty for suitable abilities of competition is basic (Kingston et al., 2010). Competition is frequently portrayed as a challenge, or a procedure of challenging, between at least two gatherings (life forms, people, or gatherings) for a rare asset or great. The scarcity can result from nature or history, for example, rivalry for constrained food, or it tends to be made misleadingly, for example, the benefit of dominating a match. The competition comes in various shapes and applies to several areas of research including sports rivalry, for instance, each has remarkable qualities, alongside certain shared traits. The competitions are organized between and among people, associations, groups, societies, nonhuman living beings, and nations, to name just the exact usually obvious. The rivalry can be prompt or aberrant, unpretentious or serious, casual or formal. It very well may be winning-losing, bringing about victors and failures, or can take into relation frequent variety of consequence appropriations (http://psychology.iresearchnet.com).

\section{Coaching leadership Style}

Studies surveying coaching results don't explain, in any case, what occurs in the training procedure by concentrating on coach practices that impact training results (Boyce \& Hernez-Broome; DeHaan, 2011). The most noteworthy productive aspect of a coach is to assist competitors with improving their athletic ability in a wide scope of errands from the consecutive turn of events and dominance of primary aptitudes, to the supplementary exacting bodily, specific, planned and psychological planning, viable training conduct fluctuates across explicit settings as the attributes of competitors and the endorsed circumstance change. The setting of the game circumstance and qualities of the coach and the players themselves direct proper initiative conduct. To accomplish improvement in athletic execution, it might be vital for the mentor to participate in training practices to which their competitor is responsive (Chelladurai, 1978). The aptitude capacity to affect an individual or bundle toward the achievement of a regular objective is compulsory (Khan et al., 2015). The scientists in the subject of sports exercises are thoroughly considering it to discover the coaching methods whereby not just specialized and strategic, motivational, the game deliberately, character-building elements can be improved but on the skills of the capability to compete of players be guaranteed and improved while 
applying fitting coaching style fit as a fiddle of democratic, autocratic or Laissez-faire coaching style which esteems fit. The primary commitment of this paper is to give down to earth proof that, what the Badminton players see about the adequacy of the democratic way of coaching on the skills of the capability to compete for 1 aptitudes of players during competitions. The idea of behavior and its style is known as an exact phase of fulfillment, inventiveness, and inspiration which is guaranteed through the coaches having democratic style with subordinates, performing with tremendous energy and quality independent of the accessibility or inaccessibility of the coaches; coaches with autocratic style, basically focusing on a huge measure of efficiency (Jung et al., 2008). The democratic coaching style is fundamentally coaching conduct in which the coach permits players in the dynamic procedure for the accomplishment of group objectives applying specialized and strategic abilities through better techniques (Asiah et al., 2009).

\section{Badminton}

Badminton is a game that is strikingly performed all over the world. This entertainment is performed at all levels employing the people having a place with unmistakable age gatherings (Shariff et al., 2009). Badminton is formally the quickest of all racket sports. Players can hit the shuttlecock at velocities of up to $180 \mathrm{mph}(288 \mathrm{kph})$ toward their rival. However, it isn't only about speed; a player can hope to approach four miles $(6.4 \mathrm{~km})$ around the court during a match while having the spryness to keep up vitality busting rallies. In this way, while endurance and deftness are significant, absolutely at a serious level, anybody can play badminton and the game is a famous decision for individuals all things considered and wellness capacities (realbuz.com). There is one help pick and his job is to name administration flaws and ten line judges who administer the bus cockerel and the strains of the court docket (Badminton world league, BWF). As per the estimation of BWF, this redirection is by and by playing with the guide of more than, 200 million people on the earth and more than a thousand took area in an assortment of contentions and rivalries around the world (Alam et al., 2009). The previous study has examined the qualities of exertion in preparing and rivalry in the play with a racket, for example, squash and tennis (Christimass, 1994). It has become conceivable to make a profile of the vivacious and physiological requests included, which has empowered the physical limit important to rehearse these games to be built up. Be that as it may, there is no adequate information on badminton to permit an increasingly practical appraisal of vitality consumption in serious matches. It isn't recognized is essential parts of execution in Badminton are, what ought to be enhanced to expand the playing category, and which components may be led to great outcomes when contenders are of a comparable level. This is intensified by obliviousness of exact parameters of a game that can be identified with execution in rivalry and their impact on the outcome. Even though badminton has expanded in fame since its consideration as an official game in the 1992, Olympic Games in Barcelona, examine on execution limit (the ideal execution category of competitors can reach, which ought to be utilized as a perspective for mentors of top players) is still rare (Manrique and GonzálezBadillo, 2003).

\section{Research Gap}

The findings of various researches demonstrate a certain effect of coaches on the players. The capability of players to compete in various sports events plays a vital role in fruitful and victorious results in any sporting event. While talking about Pakistan, especially the Sukkur region where the study was conducted, a huge quantity of players belonging to various games is those who do not have an appropriate and regular coaching environment. A large number of colleges and universities do not have their own appointed coaches. In the College education system, the Director of Physical Education (DPE) works also as a Coach of various games including Badminton. It was reported before this study, that DPEs of various colleges apply democratic coaching style to train the players through the training and coaching sessions mostly during the Badminton-tournaments in the shape of inter-collegiate organized at colleges in the Sukkur, region and inter-department tournaments at SALU, Khairpur. A good number of student-players of Badminton studying in colleges, belonging to Sukkur, region-Sindh have been resulted to participate at high-quality positions Badminton tournaments and to compete confidently in events with victorious results, for instance, inter-region, Sindh Games and national games. In this way, a question arose to find out the fact of effects of democratic coaching style on players of Badminton to contend in matches.

\section{Research Methodology}

The examination was ensured to discover the effects of democratic coaching style on the players of 
Badminton who are studying in various disciplines to contend in the competitions. Student-players of Badminton learning at Shah Abdul Latif University Khairpur (SALU) and its affiliated colleges of the Sukkur region were chosen as the population of the examination. The formulation was adopted likewise; (Saunders et al., 2018) who described the saturation confined to the level of analysis; its implication for data collection is at best implicit, whereby data was collected, as it points to the idea of pre-determined theoretical categories and leads us away from the inductive logic characteristic of grounded theory. Finally, theory linked to these data; saturation appears to be distinct from formal data analysis. Therefore, we have followed this formulation, from which the University Badminton player population was up to 425 , respectively among them we have selected 200 samples. The sample size of the investigation was from forty teams as $(\mathrm{N}=200)$ players of Badminton, as one hundred from the Colleges and one hundred from the different departments of SALU, Khairpur. The Colleges affiliated with SLU, Khairpur belonging to Sukkur, were visited by the collaboration of Directors of Physical Education (DPEs) of relevant Institutions before the beginning of research to investigate the accessibility of Badminton-players. Through the use of convenience sampling strategy, 20 colleges were chosen as an investigation sample, on the recommended by the relevant Director Sports whose student must at least have played at any rate inter-class, inter-department, inter-collegiate or intervarsity rivalries, while talking about University, Sports office of SALU organized Sports festival during the year, 2017 and different competition in sports were planned and organized where the competitions in the shape of inter-department were arranged accordingly, list along with names of players was accessible in the Sports Section of University which was utilized to get to the players for the lead of review. The examination was restricted to the understudy players (young men) of B. A part-I and II, BSC part-I and II, B. Com part-I and II of degree (boys) Colleges of region Sukkur and Badminton (young men) competitors of various divisions of SALU, Khairpur, enrolled in various disciplines and programs. The players' behavioral changes in social and psychological training and coaching through various examinations as described by (Feltz et al., 1999) and modified by Kavassanu et al., 2008 and Myers et al., 2009), respectively.

\section{Statistical Analysis}

A structured survey questionnaire, the Coaching Efficacy Scale (CES, Feltz, et al;1999) which comprises 5 domains of coaching, was used as an information assortment scale. The frequency, percentage, and mean were processed by the utilization of the Statistical Package of Social Sciences (SPSS) version 22.

Results

Table-1. Demographic information of the respondents and analysis of Democratic Coaching Style

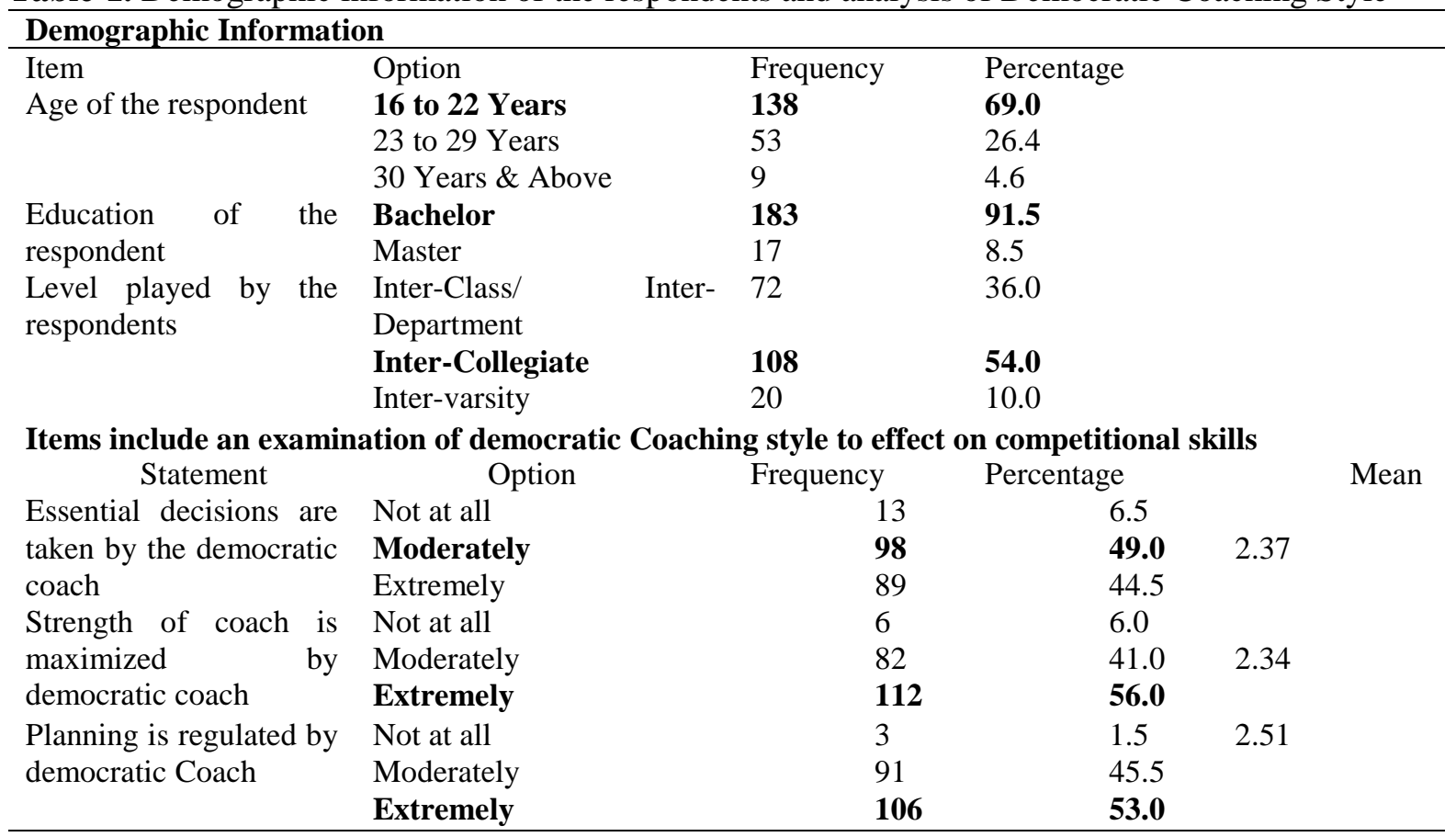


Table-1, a $\mathbf{1}^{\text {st }}$ part, demographic information analysis, which shows the majority of respondents belongs to the age group of 16 to 22 , majority of players studying in bachelor degree and maximum level played by most of the players is inter-collegiate tournaments, whereas in $2^{\text {nd }}$ part of the of table-1 we have found that the majority of the respondents have opted moderately in $1^{\text {st }}$ item, extremely in $2^{\text {nd }}$ and $3^{\text {rd }}$ item respectively which show the closest effect of democratic coaching on Badminton players to compete in matches.

Cronbach's Alpha test was led, to guarantee the consistency of data. The consequence of Cronbach's Alpha test was found as 0.92 which is solid. Table- 1 shows the age, educational level, and the playing classification of the players as partook by the respondents. As per the outcomes, as appeared in table1 , Badminton-players were having a place with the age of $16-22$ years with a maximum frequency of 138 and as $69 \%$, players belonging to the age group of 23 to 29 years with a frequency of 53 and $26.4 \%$, while the players having a place with the age of 30 years and above with least frequency 9 and $4.6 \%$. frequency of understudy players concentrating in four-year college education programs was 183 with $91.5 \%$, though in the master were 17 with $8.5 \%$. The maximum level of respondents played by them as inter-class / inter-department with frequency 72 and 36\%, Inter-collegiate with most extreme frequency 108 and 54\%, and inter-varsity with a minimum frequency of 20 and10\%. The information assortment tool that likewise incorporates proclamations for investigation of effects of democratic coaching style on the Badminton players to contend in the competitions, as referenced in the second part of the table-1. The investigation shows that greater part of responses is for beneficial outcomes of democratic coaching style on Badminton-players to contend in competitions with a most extreme frequency as of first statement $98,49 \%$ and 2.37 mean, second statement $112,56 \%$ and 2.34 mean, third proclamation 106, 53\% and mean 2.51 this assessment signifies that there are close constructive outcomes of democratic coaching style on Badminton-players to contend in competitions.

\section{Chi-square statistics}

Ho Democratic coaching style effected as negative on the players of Badminton while in the competition.

The test of Null Hypothesis was performed through the application of Chi-square and found to be rejected, as the Chi-square statistic of the statement of all values were larger than the critical Chi-Square Value is (5.99) with $\mathrm{df}=2$ and $\chi 2=49.040$, as shown in (Fig. 1).

Figure-1.shows the result of the chi-square test, the figure shows that the null hypothesis was rejected.

$\mathrm{DF}=2$

$\chi^{2}=49.040$

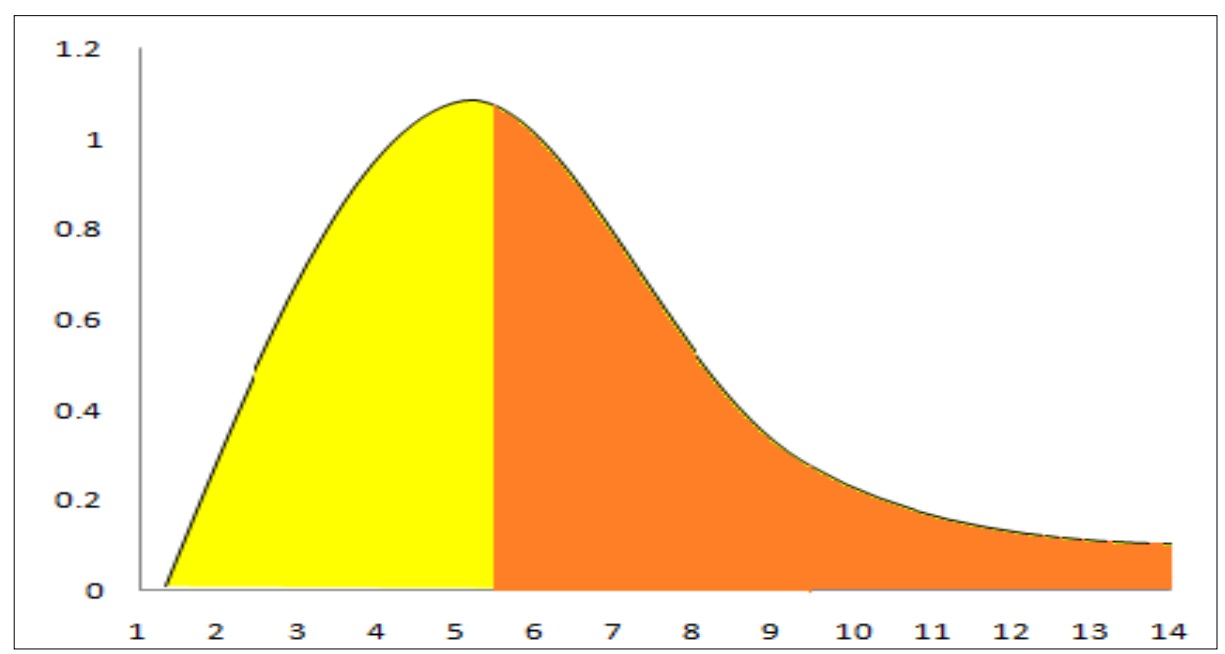

Chi-square Statistic all items values are larger than the Critical Chi-Square Value is (5.99) with $\mathrm{DF}=2$

H1 Democratic Coaching Style has a positive effect on Badminton Players to on the players of Badminton while in the competition.

Chi-square test was conducted to find out the p-value and found to be less than 0.5 


\begin{tabular}{|c|c|c|c|c|c|}
\hline Item & Observed & Expected & Chi & Df & P-value \\
\hline \multirow{4}{*}{1} & 13 & 66.7 & \multirow{3}{*}{65.410} & \multirow{4}{*}{2} & \multirow{4}{*}{0.000} \\
\hline & 98 & 66.7 & & & \\
\hline & 89 & 66.7 & & & \\
\hline & 6 & 66.7 & \multirow{3}{*}{89.560} & & \\
\hline \multirow[t]{3}{*}{2} & 82 & 66.7 & & & \multirow{3}{*}{0.000} \\
\hline & 112 & 66.7 & & 2 & \\
\hline & 3 & 66.7 & \multirow{3}{*}{92.890} & & \\
\hline \multirow[t]{2}{*}{3} & 91 & 66.7 & & 2 & \multirow{2}{*}{0.000} \\
\hline & 106 & 66.7 & & & \\
\hline
\end{tabular}

\section{Discussion}

The behavioral changes in the players in social and psychological viewpoint through training and the effects of coaching has made thought as of late with various examinations demonstrating significant results of this development for researching the instructing on players (Feltz et al., 1999) as modified by Kavassanu et al., 2008 and Myers et al., 2009. Critically, past investigation as this has not been analyzed at Sukkur, Sindh, or even though in Pakistan to look at the effects of democratic coaching style on Badminton-players to contend in the competitions, the scale to which they vary from teacher's reports related with impacts of coaching. The current investigation is thought to fill a brief hole in the field of research in coaching. Coaching in sports, its methods of coaching and its conventional procedures have been demonstrated for affecting one comfort level concerning better execution (Horn, 2008). The things of the scale as in certified scale were applied, whereby requesting that the Badminton players evaluate how their coach was capable to influence on the skills of the capability to compete for abilities of the player, anyway the analyst requested that the competitors call attention to at what sum the fair trainer is successful or how that sway on the players through the coaching while at the same time orchestrating training camps, training and even though during play or at whatever other condition where the instructing is conceivable. An improvement that has a preference for the effect of training is the viability of coaching. The relationship of instructing with players has been ending up being a degree to which the mentor accepts a thought of having could affect the learning and introduction of concerned competitors and comprises areas: motivation, game strategy, game technique, competition, and character-building of the player. Effects of democratic coaching style on Badminton-players to contend during competitions indicate away, a mentality and conduct of mentors with their players and steps of the mentors while instructing for the skills of the capability to compete for aptitudes of player (Kavussanu et al., 2008). The idea of Badminton-players for the impacts of democratic coaching style on the badminton players to contend in the competitions was inspected through the coaching efficacy scale (CES) that came about the equivalent factor course of action as the real development. Applying the comparative degree, Myers alongside social gathering (Myers et al., 2009) additionally inspected the coaching efficacy scale (CES) to break down the assessments of players for the ability of their mentors to affect the Badminton-players to contend in competitions. The aftereffects of the current research show the development in the territory of mindfulness with the most recent assessment of enthusiastic foundations of the idea for looking out the genuine information worried about the impact of training in the field of sports at the college level while applying the instructing adequacy scale (Feltz et al., 1999), specially made by Myers et, al; 2009 as a data collection tool. The determinant was advanced, support in a social point of view and goal situated conduct, in target accomplishments, capacity and certainty of the players and execution of associations required by the players, points, and destinations on the quantitative of tracks and commitment (Ryan and Tipu, 2013). The significance of popularity based coaching with the skills of the capability to compete of the players is profoundly between dependent games, for example, Badminton has been created in the writing, these outcomes add to tolerating it as mental foundations and this is a fundamental investigation on Badminton training adequacy at Sukkur Region Sindh. Additionally to comprehend the information on fair instructing and its adequacy for the player can have a diverse tendency for coaches worried about the players as described by (Khaskheli et al., (2020).

Resultantly the sports authorities and coaches will have the option to embrace vote-based instructing administration style at institutes, clubs, inter-department, inter-class, inter-collegiate, and 
inter-varsity level of training, coaching camps, and competitions to urge and to improve the players' competition aptitudes. A coach or trainer ought to have a capacity to grasp the prerequisites of the players to apply their full ability and physical capacity and to make more grounded the association of players and the coach. Along these lines; the job of a mentor is to create a level of execution of players and to produce environmental factors as an instrument to advance the inspirational disposition of the player and the analysis of this examination will allow the worried to introduce these investigated realities to the mentors and the coaches to embrace and use to improve players' competition abilities.

\section{Conclusion}

An exploration of democratic coaching in the context of its impacts on Badminton-players in the competitions has a key job in the field of sports. The popularity based training is viewed as a powerful method of improving the various abilities of the players all through the world including Pakistan. At the present status, it was to discover its effect on the competitive abilities of the player during coaching and training camps which have ultimate effects on competitions during tournaments. The current investigation indicates that there are positive outcomes of democratic coaching style ensured by DPEs on the skills of the capability to compete of the players at educational structured organizations at region-Sukkur, Sindh.

\section{Recommendations}

While analyzing the current investigation as a relationship of democratic coaching style with the competitional abilities of Badminton players and the points expected for future looks into related with coaching, effects of coaching, training in the context of authority, the viability of as on different coaching, instructing areas can be guaranteed. Besides, keeping in see the current examination, it is suggested that it tends to be applied and followed by the educators, trainers, and the coaches in sports programs just as by the teachers in educational structured organizations for the improvement of the level of skills on the capability to compete of the player and all training spaces that aren't just related with the Badminton game but the players of all games.

\section{References}

Alam, F. H., Choudhary, Ch., Thepadungporn, A., Subic \& Khan, M. M. K. (2009). International School of Aerospace, Mechanical and Manufacturing Engineering and built environment, Central Queen's land University Rockhampton Australia. J. Mech. and Material Eng., 4, pp. 266-272.

Asiah, H. J., Pilus, M. \& Saadan, R. (2009). Coaching Leadership Styles and Athlete Satisfaction among Hockey Team. J. of Human Capital Development. Vol. 2(1): pp-77-87.

Burks, S., Carpenter, J., Goette, L., \& Rustichini, A. (2013). Overconfidence and social signaling. The Review of Economic Studies, 80(3), 949-983.

Boyce, L. A., \& Hernez-Broome, G. (2011). Introduction: State of Executive Coaching: Framing Leadership Coaching Issues. In G. Hernez-Broome \& L. A. Boyce, Advancing Executive Coaching.Setting the course for successful leadership coaching (Eds.) (pp. xliii-lxi). San Francisco: John Wiley \& Sons.

Christensen, B. T., \& Ball, L. J. (2016). Dimensions of creative evaluation; Distinct design and reason strategies for aesthetic, functional, and originality judgments. Design Studies, 45 (PA), $116 \mathrm{e} 136$.

Christimass, M. A., S. E. Richmond, \& Cable, N. T. T. (1994) a metabolic characterization of single tennis. In: Reilly T, Hughes M, Lees A, ed. Science and rackets sports. London: E \& FN Spon,

Chelladurai, P., (1978). A contingency model of leadership in athletics.Unpublished doctoral dissertation, University of Waterloo, Canada.

Dunning, D., Meyerowitz, J. A. \& Holzberg, A. D. (1989). Ambiguity and self-evaluation: The role of idiosyncratic trait definitions in self-serving assessments of ability. Journal of Personality and Social Psychology, 57(6), 1082-1090.

Feltz, D.L., Chase, M.A., Moritz, S.E., \& Sullivan, P.J.(1999). A conceptual model of coaching efficacy: Preliminary investigation and instrument development. Journal of Educational Psychology, 91(4): 765-776.

Grant, A. M., Passmore, J. Cavanagh, M. \& Parker, H. (2010). The state of play in coaching.International Review of Industrial \& Organizational Psychology, 25, 125-168 
Horn, T.S., (2008).Coaching effectiveness in the sports domain. In: T.S. Horn (Ed.), Advances in sport psychology (pp. 239-267). Champaign, IL: Human Kinetics.

https://www.realbuzz.com/articles-interests/sports-activities/article/introduction-to-badminton/

http://psychology.iresearchnet.com/sports-psychology/team-building/competition-in-sports/

Jung, J., Y.J. Ahn, \& Kang, L.W. (2008). A novel approach to investigating protein/protein interactions and their functions by TAP-tagged yeast strains and their application to examine yeast transcription machinery. J. Microbiol. Biotechnol., 18(4): pp. 631-8.

Kavussanu, M., Boardly, I. D., Jutkiewiez, N., Vincent, S., \& Ring C. (2008). The Coaching efficacy and Coaching effectiveness. The Sports Psycho. 22(4): pp. 383-404.

Khan, M. S., Khan, I. Qureshi, Q. A., Ismail, H. M., Rauf, H. M., Latif, A., \& Tahir. M. (2015). The Styles of Leadership: A Critical Review. 5(3): 87-92.

Khaskheli, N. A., H. A. Sahito, \& Soomro, J. A. (2020). The Democratic way of Coaching and the Motivation of Student-Players'. Sir Syed Journal of Education \& Social Research. 3(4): (October - December issue).

Khaskheli, N. A., M. A. Ansari, H. A. Sahito, M. A. Memon \& Khaskheli, F. A. (2019). The collision of democratic coaching leadership style to improve the technical skills of badminton players. European J. Physical Edu. and Sport Science. 5(11): 83-94. doi:10.5281/zenodo.3376875

Koszegi, B., (2006). Ego utility, overconfidence, and task choice.Journal of the European Economic Association, 4(4), 673-707.

Kingston, K., A. Lane, \& Thomas, O. (2010). A temporal examination of elite performers' sources of sport-confidence. The Sport Psychologist, 18, 313-332.

Latham, G. P., (2007). Theory and research on coaching practices. Australian Psychologist, 42(4), 268-270.

Manrique, D. C., \& González-Badillo, J. J. (2003). Analysis of the characteristics of competitive Badminton. Br. J. of Sports Medicine. 37: 62-65.

McDonnell, J., (2016). Scaffolding Practices: A study of design practitioner engagement in design education. Design studies, special issue; design review conversations, 45 (part A), pp 9-29.

Myers, N. D., E. W. Wolfe, \& Feltz D. L. (2009). An evaluation of the Psychometric Properties of exercise science, 9(3): 133-105.

Pilus, A. H. M., \& Saadan R. (2009). Coaching leadership styles and athlete satisfaction among the Hockey team. J. Human Capital Develop. 2(1): 77-87.

Palmer, S. \& McDowall, A. (2010). The Coaching Relationship: Putting People First. An Introduction. In S. Palmer \& A. McDowall (Eds.), the Coaching Relationship: Putting People First (pp. 1-8). London: Routledge.

Ryan, J. C., and Tipu S. A. (2013). Leadership effects on innovation propensity: A two-factor full range leadership model, Journal of Business Research, 66, pp. 2116-2129.

Renton, J., (2009). Coaching and Mentoring: What they are and how to make the most of them. New York: Bloomberg Press. ISBN 9781576603307. OCLC263978214.

Saunders, B., Sim, J. Kingstone, T. Baker, S. Waterfield, J. Bartlam, B. Burroughs, H. \& Jinks, C. (2018). Saturation in qualitative research: exploring its conceptualization and operationalization. Quality \& quantity, 52(4): 1893-1907.

Shariff, A. H., George, J. \& Ramlan, A. A. (2009). Musculoskeletal injuries among Malaysian badminton players. Singapore Med. J., 50(11): 1095-1097.

Smith, R. E., (2010). A positive approach to coaching effectiveness and performance enhancement.Int. J. M. Williams (Ed.), New York: McGraw-Hill. Applied sport psychology: personal growth to peak performance. pp. 42-58.

Whitmore, J., (2002). Coaching for Performance.London; Nicholas Brealey Publishing. 